\title{
PELATIHAN PEMULASARAAN JENAZAH BAGI SISWA/I MTS INSAN MADANI DESA TEGALLEGA KECAMATAN CIGUDEG KABUPATEN BOGOR
}

\author{
Moh Jazuli ${ }^{1)}$, Ahmad Yani Nasution ${ }^{2)}$ \\ 1,2Program Studi Manajemen, Fakultas Ekonomi, Universitas Pamulang
}

\begin{abstract}
Abstrak
Rasulullah SAW pernah bersabda: "Barang siapa memandikan (jenazah) seorang muslim seraya menyembunyikan (aib) nya dengan baik, maka Allah akan memberikan ampunan empat puluh kali kepadanya. Barang siapa membuatkan lubang untuknya lalu menutupinya, maka akan diberlakukannya pahala seperti pahala orang yang memberikan tempat tinggal kepadanya sampai hari kiamat kelak. Barang siapa mengkafaninya, niscaya Allah akan memakaikannya sundus (pakaian dari kain sutera tipis) dan istabraq (pakaian sutera tebal) Surga di hari kiamat kelak." (HR. Al-Hakim dan Al-Baihaqi. Al-Hakim berkata; Shahih dengan syarat Muslim. Disepakati oleh Adz-Dzahabi). Latar belakang PKM INI adalah Kondisi kesedihan keluarga di mana sering mengalami ketidakmampuan dalam pengurusan jenazah. Menjadi fardhu kifayah bagi umat Islam dalam menyelenggarakan pengurusan jenazah dengan kewajiban untuk memandikan, mengkafani, menshalatkan serta menguburkan, karena rangkain prosesi pengurusan jenazah bermakna dalam nilai nilai kehidupan masyarakat. Permasalahan di atas menjadi alasan bagi kami dosen agama UNPAM untuk membentuk tim pengabdian kepada masyarakat (PKM) dan mengadakan pelatihan pemulasaraan jenazah sebagai usaha untuk membantu pengetahuan dalam pengurusan penyelenggaraan jenazah. PKM ini berjudul "Pelatihan Pemulasaraan Jenazah bagi Siswa/i MTs Insan Madani Desa Tegallega Kecamatan Desa Tegallega Cigudeg Kabupaten Bogor. PKM ini menggunakan metode ceramah yaitu dengan memberikan materi ilmu pengetahuan secara teori dan praktik. Harapannya semua masyarakat khususnya Siswa/I dapat mengetahui dan menguasai pemulasaraan jenazah agar kewajiban bersama atau fardhu kifayah dapat terlaksana dengan baik. Adapun kegiatan pelatihan ini dimaksudkan untuk mensosialisasikan peran dan fungsi serta pengkaderan amil jenazah dalam penyelenggaraan pemulasaraan jenazah. Harapannya pelatihan ini dapat memaksimalkan peran nilai-nilai humanis dan religius kemaslahatan untuk masyarakat.
\end{abstract}

Kata Kunci: Pemulasaraan, dan Jenazah

\begin{abstract}
Rasulullah SAW once said: "Whoever bathes (the corpse) of a Muslim while hiding his (shame) well, then Allah will forgive him forty times. Whoever makes a hole for him and then covers it, then he will be rewarded like the reward of the person who gave him a place to stay until the Day of Judgment. Whoever shrouds it, surely Allah will clothe him with sundus (clothes made of thin silk cloth) and istabraq (thick silk garments) Paradise on the Day of Resurrection. " (HR. Al-Hakim and Al-Baihaqi. Al-Hakim said; Sahih provided Muslim. Agreed by Adz-Dzahabi). The background of this CPM is the condition of family grief where they often experience incompetence in funeral management. It is obligatory for kifayah for Muslims in organizing the management of the corpse with the obligation to bathe, cover, pray and bury, because the procession of funeral management is meaningful in the value of community life. The problem above is the reason for us UNPAM religious
\end{abstract}


lecturers to form a community service team (CPM) and conduct funeral care training in an effort to help knowledge in the management of funeral arrangements. This PKM is entitled "Funeral Training for Students / $i$ MTs Insan Madani Tegallega Village, Cigudeg District, Bogor Regency. This PKM uses the method of lecture that is by providing science materials in theory and practice. It is hoped that all communities, especially students can know and master the funeral procession so that the joint obligation or fardhu kifayah can be implemented well. As for this training activity is intended to socialize the role and function as well as the cadre of amil corpses in the conduct of funeral arrangements. It is hoped that this training can maximize the role of humanist and religious values of benefit to society.

Keywords: Funeral, and Corpse

Correspondence author: Moh.Jazuli, dosen01680@unpam.ac.id

\section{PENDAHULUAN}

Sebuah perguruan tinggi berkewajiban melaksanakan Tri Darma Perguruan Tinggi berupa pendidikan, penelitian, dan pengabdian kepada masyarakat (P3KM). Diharapkan dengan P3KM tersebut keberadaan perguruan tinggi dapat memberikan kontribusi besar kepada pengembangan keilmuan dan pengabdian kepada masyarakat. Universitas Pamulang (Unpam) adalah salah satu Perguruan Tinggi Swasta yang secara konsisten menyelenggarakan P3KM. Pelaksanaan P3KM di Universitas Pamulang di bawah kendali Lembaga Penelitian dan Pengabdian Kepada Masyarakat (LP2M).

LP2M Universitas Pamulang memegang peranan yang sangat penting dalam mendorong dan mengarahkan kegiatan-kegiatan penelitian dan pengabdian kepada masyarakat sebagai wujud Tri Dharma Perguruan Tinggi. Setiap kegiatan P3KM yang diselenggarkan oleh seluruh Program Studi (Prodi) di Unpam harus berkoordinasi dengan LP2M. Khususnya saat ini LP2M sedang gencar mengkampanyekan Pengabdian Kepada Masyarakat (PKM). Program PKM yang akan dilaksanakan, disesuaikan dengan bidang keilmuan di setiap Prodi dan kebutuhan masyarakat.

Kehidupan manusia pasti berakhir dan akan kembali kepada Allah SWT. Oleh karena itu kematian merupakan jembatan pemisah antara kehidupan dunia dan kehidupan akhirat. Sebagaimana Allah SWT berfirman:

"Sesungguhnya kematian yang kamu lari daripadanya, maka sesungguhnya kematian itu akan menemui kamu, kemudian kamu akan dikembalikan kepada (Allah), yang mengetahui yang ghaib dan yang nyata, lalu Dia beritakan kepadamu apa yang telah kamu kerjakan". (QS. Al-Jumu'ah: 08).

Oleh karena itu jika mampu membawa amalan baik maka keberuntungan yang akan didapat, Begitupun sebaliknya. kematian sewaktu-waktu pasti akan datang, banyak hal yang tidak disiapkan oleh keluarga jenazah. Oleh karena itu, kewajiban sebagai seorang muslim untuk mengurus jenazah sebagaimana Rasulullah SAW pernah bersabda:

"Barang siapa memandikan (jenazah) seorang muslim seraya menyembunyikan (aib)nya dengan baik, maka Allah akan memberikan ampunan empat puluh kali kepadanya. Barang siapa membuatkan lubang untuknya lalu menutupinya, maka akan diberlakukannya pahala seperti pahala orang yang memberikan tempat tinggal 
kepadanya sampai hari kiamat kelak. Barang siapa mengkafaninya, niscaya Allah akan memakaikannya sundus (pakaian dari kain sutera tipis) dan istabraq (pakaian sutera tebal) Surga di hari kiamat kelak." (HR. Al-Hakim dan Al-Baihaqi. Al-Hakim berkata; Shahih dengan syarat Muslim. Disepakati oleh Adz-Dzahabi).

Mengurus jenazah adalah orang yang lebih mengetahui sunnahnya. Jenazah lakilaki diurus oleh orang yang telah ditunjuk oleh si mayit sendiri sebelum wafatnya (berdasarkan wasiatnya). Kemudian ibunya, anak wanitanya, keluarga dekat mayit. Suami diperbolehkan mengurus jenazah orang kafir (QS. At- Taubah : 84).

Saat ini belum banyak masyarakat yang mengetahui tata cara penyelenggaraan jenazah yang mengidap penyakit menular. Pada umumnya mereka melakukan standar yang sama dalam mengurus jenazah, khususnya saat memandikan mayat. Hal ini sangat penting untuk diketahui, mengingat resiko yang ditimbulkan cukup berbahaya. Berdasarkan deskripsi di atas, maka perlu dilakukannya pelatihan dan keterampilan pemulasaran jenazah bagi Siswa/i MTs Insan Madani Kecamatan Cigudeg Kabupaten Bogor karena:

a. Siswa/i MTs Insan Madani Kecamatan Cigudeg Kabupaten Bogor termasuk generasi yang akan menjadi penerus di Kampung tersebut. Kesibukan masyarakat dalam mencari kehidupan seperti Bertani, berkebun dll, membuat mereka adakalanya memiliki keterbatasan untuk menuntut ilmu agama termasuk dalam hal penyelenggaraan pengurusan jenazah. Masyarakat lebih memilih meminta bantuan Ustadz atau guru sekitar untuk mengurus jenazah keluarga mereka daripada mengurusnya sendiri. Oleh karena itu, perlu adanya pemberdayaan masyarakat kaitannya dengan perawatan jenazah, sehingga jika suatu saat dibutuhkan mereka siap untuk mengurus jenazah keluarga mereka sendiri.

b. Tidak banyak ustad atau guru yang faham sekaligus dapat mempraktekan pengurusan jenazah. Akibatnya Jika ustadz atau guru berhalangan karena kesibukan lain seperti sedang bekerja dan keluar kota. Bisa dipastikan jenazah akan terabaikan karena harus menunggu ustad atau guru tersebut. Oleh karena itu perlu adanya pelatihan terhadap masyarakat dalam hal ini di mulai dari para penerus mereka yaitu para siswa Mts. Dengan pelatihan tersebut, maka nantinya banyak harapan generasi yang mampu mengurus jenazah dengan baik, sehingga tidak kesulitan jika ustad atau guru sakit atau terdapat halangan.

\subsection{Analisis Situasi Permasalahan}

Kesedihan keluarga sering dirasakan dan dialami karena ketidakmampuan keluarga sendiri dalam pengurusan jenazah sehingga harus menunggu para ustadz atau ustadah untuk mengurus jenazah bagi keluarga yang meninggal di mana kadang para ustadz yang diharapkan tidak ada di tempat dan lain sebagainya sehingga proses pemulasaraan jenazah sedikit terhambat. Jika terjadi hal demikian Maka menjadi fardhu kifayah bagi umat Islam dalam menyelenggarakan pengurusan jenazah. Dengan kewajiban untuk memandikan, mengkafani, menshalatkan serta menguburkan. karena rangkain prosesi pengurusan jenazah bermakna dalam nilai nilai kehidupan masyarakat yang harus dikerjakan. 


\subsection{Rumasan Masalah}

Permasalahan di atas menjadi alasan bagi kami dosen agama UNPAM untuk membentuk tim pengabdian kepada masyarakat (PKM) dan mengadakan pelatihan pemulasaraan jenazah sebagai usaha untuk membantu pengetahuan dalam pengurusan penyelenggaraan jenazah. PKM ini berjudul "Pelatihan Pemulasaraan Jenazah bagi Siswa/i MTs Insan Madani Kecamatan Cigudeg Kabupaten Bogor".

\subsection{Tujuan PKM}

Adapun kegiatan pelatihan ini dimaksudkan untuk mensosialisasikan peran dan fungsi serta pengkaderan amil jenazah dalam penyelenggaraan pemulasaraan jenazah. Harapannya pelatihan ini dapat memaksimalkan peran nilai-nilai humanis dan religius kemaslahatan untuk masyarakat.

\subsection{Manfaat Pengabdian}

Manfaat dari kegiatan PKM ini adalah :

1). Peserta Didik khususnya Siswa/i Mts Insan Madani Kecamatan Cigudeg Kabupaten Bogor Mendapatkan Pelatihan baik teori mapun Praktek dari Pelatihan Pemulasaraan Jenazah sehingga dapat memperkaya pengetahuan dan pemahaman para siswa khususnya berkenaan dengan pemulasaraan jenazah

2). Peserta didik mampu memahami dan mempraktikan Pemulasaraan Jenazah dan dapat digunakan di Masyarakat jika diperlukan.

\subsection{Tempat dan waktu}

Pengabdian Masyarakat dengan tema "Pelatihan Pemulasaraan Jenazah bagi Siswa/i MTs Insan Madani Kecamatan Tegallega Cigudeg Kabupaten Bogor" akan dilaksanakan pada:

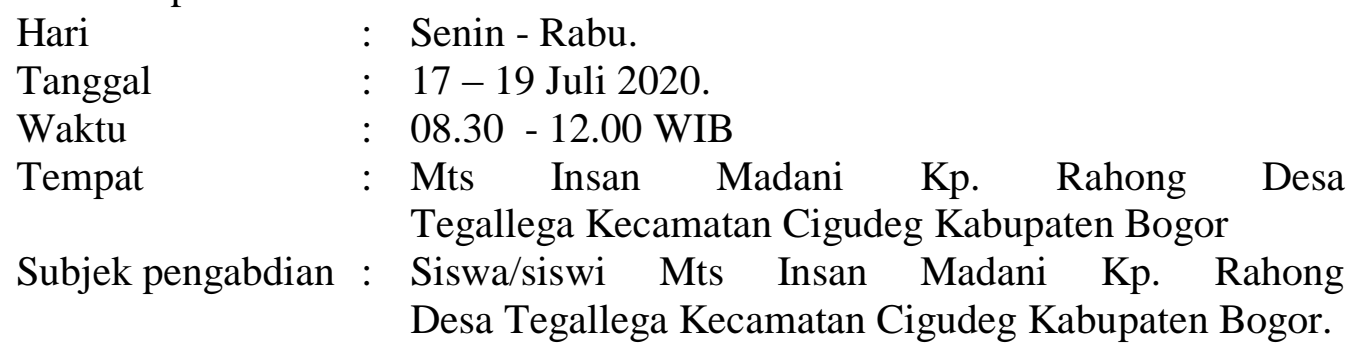

\subsection{Tahapan dan Pelaksanaan PKM:}

1). Tahap Persiapan
a. Survei awal, pada tahap ini, dilakukan wawancara dengan kepala sekolah Mts Insan Madani Kp. Rahong Desa Tegallega Kecamatan Cigudeg Kabupaten Bogor terkait prosedur kegiatan PKM.
b. Pemantapan lokasi dan peserta PKM.
c. Penyusunan bahan pelatihan PKM. 
2). Tahap Pelaksanaan Pelatihan
a. Pembukaan
b. Pelaksanaan Pelatihan
c. Games/permainan
d. Penutup

\subsection{Tinjauan Pustaka}

Penyelanggaraan jenazah yang biasa dilakukan dalam masyarakat memang berbeda-beda tradisinya. Namun hal-hal yang bersifat sunah tentu tidak ada perbedaan. Pandangan inilah yang mendasari perlunya dilakukan upaya pelatihan. Zainimal (2010) secara khusus Nabi memberi-kan tuntunan dalam perawatan jenazah ini yang meliputi memandikan jenazah, mengkafani, menshalatkan, sampai menguburkannya. Dalam hal ini Nabi tidak memberikan aturan yang rinci, hanya ketentuan umum saja yang memper-mudah kita umat Islam untuk mengembangkannya sendiri di tengah masyarakat yang memiliki budaya yang berbeda-beda. Namun secara khusus Nabi juga memberikan rambu- rambu mana yang harus dilakukan dan mana yang tidak boleh dilakukan. Di samping petunjuk Nabi Saw, tata cara penyelenggaraan jenazah juga harus mengikuti petunjuk dokter, terutama tata cara memandikan mayat yang terkena penyakit menular agar tidak menimbulkan bahaya menular bagi yang memandikannya. Seperti menggunakan sarung tangan, baju, dan mengacu pada protap (protokol tetap) tata cara memandikan jenazah penderita penyakit menular. Ini dimaksudkan demi kemaslahatan diri maupun orang lain. "Dan janganlah kamu menjatuhkan dirimu sendiri dalam kebinasaan” (alBaqarah [2]:195). Begitu pula sabda Nabi SAW: "janganlah mendatangkan bahaya bagi diri sendiri dan kepada orang lain”. (H.R. Ibnu Majah).

Adapun kaifiyat pemulasaraan jenazah adalah Ketika meninggal, dalam Islam dituliskan aturan, syarat, serta cara dalam mengurus jenazah. Termasuk di dalamnya bagaimana mengurus Jenazah muslimah mulai dari memandikan, menyolati, hingga menguburkan. Untuk urusan memandikan jenazah muslimah, maka wajib diserahkan kepada sesama muslimah. Tidak diperbolehkan seorang laki-laki baik saudara, suami, maupun anak untuk turut serta. Adapun syarat bagi yang ingin memandikan jenazah adalah muslim, berakal, mumayiz, terpercaya, amanah, dan paham atas hukum-hukum memandikan jenazah.

Hukum memandikan jenazah ini fardhu kifayah. Berdasarkan hadis dari Abdullah bin Abbas, "Ada seorang lelaki yang sedang wukuf di Arafah bersama Nabi SAW. Tiba-tiba ia terjatuh dari hewan tunggangannya lalu meninggal. Maka Nabi bersabda: 'mandikanlah ia dengan air dan daun bidara. Dan kafanilah dia dengan dua lapis kain, jangan beri minyak wangi dan jangan tutup kepalanya. Karena Allah akan membangkitkannya di hari Kiamat dalam keadaan bertalbiyah'."

Dikisahkan pula oleh Ummu Athiyyah dalam HR Bukhari, "Salah seorang putri Nabi SAW meninggal (yaitu Zainab). Maka beliau keluar dan bersabda: 'mandikanlah ia tiga kali, atau lima kali atau lebih dari itu jika kalian menganggap itu perlu. Dengan air dan daun bidara. Dan jadikanlah siraman akhirnya adalah air yang dicampur kapur barus, atau sedikit kapur barus. Jika kalian sudah selesai, maka biarkanlah aku masuk. 
Ketika kami telah menyelesaikannya, maka kami beritahukan kepada beliau. Kemudian diberikan kepada kami kain penutup badannya, dan kami menguncir rambutnya menjadi tiga kunciran, lalu kami arahkan ke belakangnya."

Beberapa proses atau tahapan memandikan jenazah yaitu pertama jenazah ditempatkan di tempat pemandian yang tertutup dari pandangan manusia lainnya. Kedua di dalam pemandian tidak boleh ada orang selain yang akan memandikan jenazah atau membantu proses pemandian. Selanjutnya meletakkan kain penutup diatas aurat jenazah dari pusar sampai kedua lutut jika mayat laki-laki dan dari dada sampai kedua lutut jika jenazahnya perempuan.

Langkah selanjutnya adalah melepaskan seluruh baju dan membungkukkan jenazah dengan mengangkat kepalanya hampir dalam keadaan duduk. Hal ini dilakukan untuk membersihkan sisa-sisa kotoran di bagian belakang. Membersihkan kemaluan jenazah dengan kain lalu mewudhukan jenazah. Setelahnya membersihkan badan dengan sarung tangan yang lain. Jenazah kemudian disiram dengan buih air sidr (daun sidr).

Dalam memandikan jenazah dimulai dari kanan depan, lalu kanan belakang, kiri depan lalu kiri belakang yang dilakukan sebanyak tiga kali. Selanjutnya menyirami seluruh tubuh jenazah dengan menggunakan air dari kapur barus. Mengeringkan jenazah dilakukan dengan menggunakan handuk.

Bagi jenazah laki-laki rambutnya harus disisir, sementara bagi jenazah muslimah dikepang tiga kali. Terakhir bagi yang memandikan jenazah dan berwudhu bagi yang membawa jenazah disunnahkan mandi setelahnya.

Setelah dimandikan, jenazah wajib dikafani. Bagi jenazah wanita, dianjurkan menggunakan lima helai kain berwarna putih. Mengkafani jenazah adalah sekedar menutup seluruh tubuhnya dengan bagus. Dalam HR Muslim Nabi bersabda, "Apabila salah seorang diantara kalian mengkafani saudaranya, maka hendaklah memperbagus kafannya."

Jumhur ulama berpendapat disunahkan bagi_jenazah muslimah menggunakan lima helai kain kafan. Namun, hadis tentang hal ini lemah. Maka dalam hal ini perkaranya longgar, boleh hanya dengan tiga helai, namun lima helai juga lebih utama.

Syaikh Muhammad bin Shalih Al Utsaimin berkata dalam Asy Syarhul Mumti, "Dalam hal ini telah ada hadits marfu' (kafan seorang wanita adalah lima helai kain). Akan tetapi, di dalamnya ada seorang rawi yang majhul (tidak dikenal). Oleh karena itu, sebagian ulama berkata: "Seorang wanita dikafani seperti seorang lelaki. Yaitu tiga helai kain, satu kain diikatkan di atas yang lain."

Perihal menyolati jenazah, hukumnya fardhu kifayah. Bagi yang menjalankan, maka akan menjadi amalan yang besar baginya. Imam Bukhori dari Abu Hurairah menyatakan bahwa Rasulullah SAW pernah bersabda, "Barangsiapa yang menyaksikan jenazah sehingga dia menshalatkannya maka baginya satu qirath dan barangsiapa yang menyaksikannya sehingga menguburkannya maka baginya dua qirath. Lalu Rasulullah ditanya, 'Seberapakah dua qirath itu?', beliau saw menjawab, 'Seperti dua buah gunung yang besar'."

Posisi berdiri iman adalah di tengah-tengah jenazah apabila jenazahnya perempuan dan di kepala jenazah apabila jenazahnya adalah laki-laki. Disyariatkan untuk menshalati jenazah di kuburan jika jenazahnya tertinggal dan terlanjur dikubur. 
Tidak ada larangan bagi wanita untuk ikut melaksanakan shalat jenazah. Ummu Athiyah dalam HR Muslim berkata, "Kami pernah dilarang untuk mengiringi jenazah namun kami tidaklah ditekankan (di dalampelarangan itu)."

Dalam HR Muslim lainnya disebutkan zaman dahulu terdapat kisah mengenai wanita yang melakukan shalat jenazah. "Ketika Sa'ad bin Abi Waqqash meninggal dunia, istri-istri Nabi SAW meminta agar jenazahnya di bawa ke masjid agar mereka dapat menshalatkannya, kemudian hal itu mereka lakukan."

Syekh Ibnu Utsaimin rahimahullah ditanya, "Apakah seorang wanita dibolehkan berkumpul di salah satu rumah wanita, dan mereka shalat jenazah kepada mayat di rumah itu?" Beliau menjawab, "Ya, tidak mengapa seorang wanita melakukan shalat jenazah. Baik dia shalat di Masjid bersama orang-orang Atau dia shalat (jenazah) di rumah jenazah. Karena para wanita tidak dilarang menshalati jenazah."

\section{METODE PELAKSANAAN}

Bentuk solusi yang ditawarkan untuk menyelesaikan persoalan prioritas di atas adalah melaksanakan pelatihan pengurusan jenazah bagi warga masyarakat, khususnya terhadap Siswa/i MTs Insan Madani Desa Tegallega Kecamatan Cigudeg Kabupaten Bogor. Rencana dan strategi kegiatan keislaman terhadap mitra dilaksanakan dengan beberapa langkah strategis yaitu;

1). Penjajakan atau survey lapangan. Pada tahap ini, tim PKM dosen unpam melakukan pengamatan, dan wawancara dalam rangka pengumpulan data awal dari warga mitra.

2). Membuat kesepakatan dengan warga mitra berkenaan dengan metode, strategi, dan agenda-agenda yang perlu dilakukan untuk mengatasi masalah prioritas yang dihadapi mitra.

3). Mengadakan pelatihan pemulasaraan jenazah (tajhiz mayit). Kegiatan pelatihan dipusatkan di Kp. Rahong Desa Tegallega Kecamatan Cigudeg Kabupaten Bogor diikuti oleh para siswa/I dan Guru MTS Insan Madani.

4). Tahap evaluasi, yaitu kegiatan penilaian terhadap kemampuan mitra setelah mengikuti pelatihan. Evaluasi dimaksudkan untuk mengetahui tingkat keberhasilan warga dalam menyerap materi pelatihan dan mengukur apakah program pelatihan berhasil atau tidak. Indikator keberhasilan pelatihan ini dapat diukur dari keberhasilan peserta pelatihan dalam menyerap materi yang diberikan. Ada 2 model test yang akan diberikan kepada peserta pelatihan, yaitu; test awal, dan test akhir. Tes awal diadakan pada saat sebelum mengikuti kegiatan pelatihan yang bertujuan untuk mengetahui kadar kemampuan peserta tentang kaidah-kaidah tajhiz mayit. Test akhir diadakan dengan tujuan untuk mengetahui sejauhmana kemampuan peserta tentang materi- materi yang sudah disampaikan. Hal-hal yang dievaluasi adalah berkenaan dengan kemampuan teoritis dan keterampilan dalam menyelenggarakan pengurusan jenazah. Dalam hal ini teknik penilaian yang dilakukan berupa test lisan (tanya jawab), tulisan, dan penampilan (performance).

Instrumen yang digunakan bersifat teoritis dan praktis. Instrumen teoritis dilakukan di dalam ruangan tertutup melalui teknik ceramah, tanya jawab, dan dialog tentang kaidah-kaidah tajhiz mayit. Seperti halnya metode pengajaran teoritis, kemudian pelaksanaan bimbingan secara praktis juga dilakukan agar lebih sempurna. Bimbingan 
praktis dilaksanakan melalui teknik peragaan, dan demonstrasi yang diadakan di halaman MTs Insan Madani Kecamatan Cigudeg Kabupaten Bogor.

Kegiatan ini dilaksanakan pada siang hari, mulai dari pukul $08.00 \mathrm{~s} / \mathrm{d} 12.00 \mathrm{Wib}$ selama 3 hari tatap muka. Kepada setiap peserta pelatihan diberikan modul pelatihan yang berisikan tentang hak dan kewajiban antara sesama Muslim, hukum dan kedudukan tajhiz mayit, serta tata cara penyelenggaraan jenazah berdasarkan sunnah Nabi.

\section{HASIL DAN PEMBAHASAN}

Soft skill merupakan kualitas yang dibutuhkan dalam beberapa hal tertentu yang tidak berdasarkan pada kemampuan pengetahuan. Kemampuan ini meliputi pola pikir, kemampuan negosiasi, dan sikap yang lentur secara positif. Kemampuan ini akan sangat bermanfaat dalam dunia kerja maupun dalam interaksi sosial pada umumnya.

Keterampilan tersebut tidak tumbuh dengan banyaknya buku yang dibaca ataupun banyaknya pelatihan keahlian yang sudah diikuti. Kemampuan secara sosial seperti yang disebutkan di atas adalah kemampuan teknis yang terbentuk berdasarkan pengalaman. Maka, untuk mengembangkan soft skill, kuncinya adalah terus mengasahnya.

Soft skill sangat berguna jika dibarengi dengan hard skill yang mumpuni. Seorang profesional dengan kemampuan intelektual atau praktik tinggi akan percuma jika tidak memiliki kemampuan menyampaikan gagasan, tidak bisa bernegosiasi, tidak bisa berkomunikasi dengan baik atau bahkan tidak mampu menempatkan diri dengan baik di lingkungannya.

Penguasaan kemampuan-kemampuan tersebut sangat penting di era sekarang ini. Banyak contoh seseorang dengan kemampuan intelektual dan praktik yang baik namun kurang bisa menempatkan diri dalam lingkungannya. Akibatnya, mereka tidak bisa bekerja sama dengan orang lain dalam tim, bahkan tidak memiliki kemampuan menyampaikan gagasan yang baik. Dalam kenyataannya, tak jarang mereka malah menempatkan anggota tim yang lain dalam kesusahan sehingga berakibat buruk pada yang lainnya.

Untuk memberi bekal softskill ini, yang dilakukan TIM PKM kepada siswa dan siawi MTs dengan memberikan pelatihan Pemulasaraan Jenazah yang benar dan baik. Berikut ini merupakan tata cara mengurus jenazah yang baik:

\section{A. Perawatan Jenazah}

Ketika seseorang sudah dinyatakan positif meninggal, maka ada beberapa hal yang perlu disegerakan oleh keluarganya dalam mengurus jenazah tersebut, yaitu memandikan, mengkafani, menyalati dan menguburkan.

Namun, kita juga perlu melakukan hal-hal berikut sebelum memandikan jenazah, diantaranya adalah memejamkan matanya dan memohonkan ampunan atas segala dosanya pada Allah swt. Setelah itu kita memerlukan kain untuk menutup seluruh badannya agar auratnya tidak kelihatan. Kemudian menempatkan jenazah tersebut di tempat yang aman dari jangkauan binatang. 


\section{B. Memandikan Jenazah}

Dalam memandikan jenazah kita juga perlu memperhatikan beberapa hal, di antaranya yaitu mengenai syarat-syarat wajib memandikan jenazah, orang-orang yang mempunyai hak memandikan jenazah, dan kemudian tata cara memandikan jenazah itu sendiri. Berikut adalah pembahasannya:

\section{Syarat - Syarat Wajib Memandikan Jenazah}

1). Jenazah merupakan orang Islam

2). Terdapat/masih ada bagian tubuhnya walaupun sedikit.(misalkan ketika orang tersebut tertabrak kereta sehingga tubuhnya hancur berkeping-keping, namun masih ditemukan bagian tubunya seperti kaki, maka itu wajib untuk dimandikan).

3). Meninggalnya bukan karena mati syahid (mati dalam peperangan ketika membela agama Islam).

\section{Yang berhak memandikan jenazah}

1). Jika jenazah tersebut berjenis kelamin laki-laki maka yang wajib memandikannya juga laki-laki, perempuan tidak diperbolehkan memandikan jenazah tersebut kecuali istri dan mahramnya.

2). Jika jenazah tersebut berjenis kelamin perempuan maka yang wajib meamandikannya adalah perempuan, laki-laki tidak diperbolehkan memandikan jenazah tersebut kecuali suami dan maharamya.

3). Jika jenazah tersebut merupakan seorang istri, maka apabila suami dan mahram masih ada, yang lebih berhak memandikan adalah suami.

4). Jika jenazah tersebut merupakan seorang suami, maka apabila istri dan mahramnya masih ada, yang lebih berhak memandikan adalah istri

5). Kemudian jika jenazah tersebut adalah anak laki-laki yang masih kecil, perempuan diperbolehkan untuk memandikannya. Begitu pula sebaliknya, jika jenazah tersebut anak perempuan yang masih kecil, maka laki-laki diperbolehkan untuk memandikannya.

\section{Tata Cara Memandikan Jenazah}

1). Jenazah harus dimandikan di tempat yang tertutup, agar yang melihat hanya orang-orang yang memandikan saja.

2). Jenazah di tempatkan di tempat yang tinggi, seperti dipan atau meja yang panjang.

3). Menggunakan sarung unruk menutup aurat jenazah.

4). Jenazah didudukkan atau disandarkan pada sesuatu, kemudian diusap perutnya dan ditekan pelan- pelan agar semua kotorannya keluar. Lalu yang memandikan menggunakan sarung tangan kiri untuk membasuh lubang depan dan lubang belakang jenazah, dan kemudian membersihkan mulut dan hidung jenazah, setelah itu mewudhukannya seperti wudhunya orang yang masih hidup.

5). Membasuh kepala dan wajah jenazah dengan menggunakan sabun atau lainnya, kemudian menyisir rambutnya. 
6). Membasuh seluruh tubuh dimulai dari sisi kanan jenazah, kemudian sisi kirinya. (disunahkan membasuh sebanyak 3 kali)

\section{Mengkafani Jenazah}

Kain kafan dibeli menggunakan harta dari orang yang meninggal tersebut. Apabila jenazah tersebut adalah laki-laki maka membutuhkan kain kafan tiga lapis, namun apabila jenazah tersebut adalah perempuan maka membutuhkan kain kafan sebanyak lima lapis, dan itu sudah termasuk yang digunakan sebagai pakaian dalaman/basahan jenazah.

Dalam HR.Muslim, Abu Salamah ra bercerita bahwa ia pernah bertanya pada "Aisyah ra. "Berapa lapiskah kain kafan Rasulullah saw.?" "Tiga lapis kain kafan putih." Jawab 'Aisyah. Disunahkan pula untuk memberi wewangian pada kain kafan.

\section{Tata Cara Mengkafani Jenazah}

1). Membentangkan tali-tali pengikat kain kafan secukupnya.

2). Membentangkan lapis pertama kain kafan di atas tali tersebut kemudian ditambahkan wewangian.

3). Membentangkan lapis kedua kain kafan di atas lapis pertama kain kafan kemudian ditambahkan wewangian.

4). Membentangkan lapis ketiga kain kafan di atas lapis kedua kain kafan kemudian ditambahkan wewangian.

5). Letakkan jenazah pada kain kafan tersebut.

6). Tutup menggunakan kain kafan lapis ketiga dari sisi kiri ke kanan, lalu dari sisi kanan ke kiri.

7). Tutup menggunakan kain kafan lapis kedua dari sisi kiri ke kanan, lalu dari sisi kanan ke kiri.

8). Tutup menggunakan kain kafan lapis pertama dari sisi kiri ke kanan, lalu dari sisi kanan ke kiri. Kemudian mengikat jenazah dengan tali-tali tadi.

\section{SIMPULAN}

Kegiatan Pengabdian Kepada Masyarakat dengan tema "Pelatihan Pemulasaraan Jenazah di Mts Insan Madani Kp. Rahong Desa Tegallega Kecamatan Cigudeg Kabupaten Bogo Bogor" yang telah dilaksanakan oleh tim pengabdian kepada masyarakat program studi Manajemen Universitas Pamulang terlaksana dengan baik sesuai dengan yang direncanakan. Kegiatan berlangusng selama tiga hari. Acara ini terlaksana atas kerjasama dengan berbagai pihak seperti Yayasan Sasmita Jaya, dosen Program Studi Manajemen serta lembaga pendidikan Mts Insan Madani Kp. Rahong Desa Tegallega Kecamatan Cigudeg Kabupaten Bogo Bogor. Pelatihan ini berhasil memberikan bekal softskill kepada siswa/ siswi Mts Insan Madani Kp. Rahong Desa Tegallega Kecamatan Cigudeg Kabupaten Bogor.

Saran dari pelatihan menangkal degradasi moral dalam rangka kegiatan pengabdian kepada masyarakat ini adalah hendaknya tim dosen ataupun berbagai pihak lainnya turut serta dalam mendukung program untuk membuat para generasi muda, khususnya Siswa/ 
siswi MTs Insan Madani agar mempunyai bekal moral yang baik yang berguna bagi mereka. Tidak hanya itu anak-anak remaja memang harus diarahkan dan dibantu agar tidak hanya cerdas dalam akdemis tapi juga mempunyai kemampuan softskill yang baik, terutama baik anak-anak remaja yang sedang mencari jati diri. Harapannya pelatihanpelatihan semacam ini dapat terus dilaksanakan dan ditingkatkan jenjang pendidikan

Kegiatan pengabdian kepada masyarakat adalah salah satu kewajiban dosen untuk memenuhi kewajiban Tri Dharma Perguruan Tinggi yang menjadi aksi dari keterlibatan perguruan tinggi dalam pembangunan nasional. Dari kegiatan ini, masyarakat juga akan mendapatkan bekal untuk menyelesaikan permasalahan dan menjawab tantangan dalam kehidupannya. Masyarakat juga nantinya akan memberikan pembelajaran bagi perguruan tinggi tentang realitas kehidupan. Diharapkan PKM yang dilaksanakan dengan sasaran Siswa/siswi Mts Insan Madani Kp. Rahong Desa Tegallega Kecamatan Cigudeg Kabupaten Bogo Bogor ini dapat bermanfaat kepada semua pihak yang terlibat baik secara langsung ataupun tidak. Selain itu diharapkan PKM ini dapat menginspirasi berbagai pihak untuk terus mendukung berbagai kegiatan yang serupa.

\section{DAFTAR PUSTAKA}

Al-Uraifi, Abdul Aziz Bin Muhammad. (2006). Fatwa-Fatwa Seputar Jenazah. Surabaya: Pustaka Elba.

Karim, Abdul. (2012). Petunjuk Shalat Jenazah dan Permasalahannya. Jakarta.

Amzah, Abdullah Muhammad Bin Yazid al-Quzwaini. (2004). Sunan Ibnu Majah I Beirut: Dar al-Fikr.Ahmad

Aziz, Abdul Fatah. (2010). Cara Mudah Belajar Tahiz mayit. Jakarta: Embun Publishing Hartati. (2013). Pedoman Penyelenggaraan Jenazah. Jakarta: Rineka Cipta.

Rusyd, Ibnu. Bidayah al-Mujtahid wa Nihayah al-Muqtashid I. Beirut: Dar al-Jail. Uwaidah, Syaikh Kamil Muhammad. (2008). Fiqih Wanita. Jakarta: al-Kauthar.

Nasution, Lahmudin. (1999). Fiqih Ibadah. Jakarta: Logos Wacana Ilmu.

Rifa'i, Moh. (1978). Ilmu Fiqih Islam Lengkap. Semarang: Karya Toha Putra

Nurdan, dkk. (2012). Bimbingan Praktis Mengurus Jenazah. Lhokseumawe: Lembaga Fastabikhul Khairat

Al-Hanif, Rifki. (2007). Pedoman Teoritis dan praktis Tahiz mayit. Bandung: Al Husna Ahjad, Nadjih. (1991). Kitab Jenazah. Jakarta: Bulan Bintang

Sabri. (2012). Tuntunan Praktis Perawatan Jenazah. Semarang: Pustaka Nuun

Amir, Syafrudin. (2009). Buku Praktis Menyelenggarakan Jenazah. Jakarta: Cinta Buku Media

Zainimal. (2010). Buku Saku Tentang Tata Cara Penyelenggaraan Jenazah. Jakarta: Pelita Ilmu. 